\title{
OPTIMASI PROSES PEMBUATAN BRIKET BIOMASSA MENGGUNAKAN METODE TAGUCHI GUNA MEMENUHI KEBUTUHAN BAHAN BAKAR ALTERNATIF YANG RAMAH LINGKUNGAN \\ (Optimization of Biomass Briquettes Production Process Using Taguchi Method to Fulfill The Need of Environment Friendly Alternative Fuel)
}

\author{
Musabbikhah*, Harwin Saptoadi, Subarmono dan Muhammad Arif Wibisono \\ Fakultas Teknik, Jurusan Teknik Mesin dan Industri, Universitas Gadjah Mada, \\ Jln. Grafika no 2, Yogyakarta 55281. \\ *Penulis korespondensi. No Tel: 081329286067. Email: moesika12@gmail.com.
}

Disetujui: 4 Maret 2015

\begin{abstract}
Abstrak
Permasalahan yang dihadapi pembuat dan pengguna briket adalah briket yang dihasilkan kualitasnya rendah ditinjau dari nilai kalor. Tujuan penelitian ini adalah menentukan kualitas briket terbaik dari limbah biomassa dalam memenuhi kebutuhan bahan bakar alternatif rumah tangga yang murah dan ramah lingkungan guna mewujudkan masyarakat mandiri energi. Metode yang digunakan untuk menentukan kualitas briket adalah metode Taguchi. Variabel bebas dalam penelitian ini adalah tekanan pengepressan, waktu penahanan, model cetakan, suhu pengeringan, lama pengeringan dan komposisi bahan, sedangkan variabel terikat adalah nilai kalor briket. Hasil penelitian menunjukkan bahwa kualitas briket terbaik ditinjau dari nilai kalor tertinggi yaitu pada setting parameter A2B1C2D2E2F1, artinya tekanan pengepressan $225 \mathrm{~kg} / \mathrm{cm}^{2}$, waktu penahanan 5 menit, model cetakan sarang tawon (kotak), suhu pengeringan 60 ${ }^{\circ} \mathrm{C}$, lama pengeringan 3 hari, perbandingan limbah jarak pagar (Jatropha Curcas) : arang sekam : arang tempurung kelapa : perekat adalah $5: 3: 2$ : 1. Rata-rata nilai kalor biobriket yang dihasilkan sebesar $5.323 \mathrm{kal} / \mathrm{g}$. Hal ini menunjukkan bahwa briket mempunyai nilai kalor yang tinggi dan memenuhi SNI, sehingga briket layak untuk memenuhi kebutuhan bahan bakar alternatif yang ramah lingkungan.
\end{abstract}

Kata kunci: bahan bakar, briket, biomassa, energi alternatif, limbah padat, nilai kalor,ramah lingkungan.

\begin{abstract}
Problems that encountered on manufacturers and users of briquettes is low quality of the briquettes in terms of heat value. The aim of this research is to determine the best quality of the briquette which is made from biomass waste. The briquette is expected to be used to fulfill the need of inexpensive and environmentally friendly of alternative household fuel, by which the energy independent community could be realized.The method used to determine the quality of the briquette is Taguchi method. The independent variables involved are compressive strength, holding time, mold model, drying temperature, drying time and material composition. The dependent variable is the highest heat value of the briquette. The results show that based on the highest heat value, the best briquette quality is parameter setting of A2B1C2D2E2F1, which means that the compressive strength is $225 \mathrm{~kg} / \mathrm{cm}^{2}$, the holding time is 5 minutes, the mold model is honeycomb of box, drying temperature is $60{ }^{\circ} \mathrm{C}$, drying time is 3 days and the ratio of Jatropha Curcas waste : rice husk charcoal : coconut shell charcoal : adhesive is $5: 3: 2: 1$. The average heat value of briquette is 5,323 cal/g. This matter the briquettes show that high heat value and feasible of recommendation by SNI, and so briquette decent to fulfill the need of environment friendly alternative fuel.
\end{abstract}

Keywords: alternative energy, briquette, biomass, charcoal, environment friendly, heat value, solid waste.

\section{PENDAHULUAN}

Berdasarkan data BPS Kab. Boyolali (Anonim, 2007), terdapat 40,48\% warga Boyolali termasuk kategori keluarga miskin. Menurut Wardono (2010), budi daya tanaman jarak pagar di Desa Gondangrawe Kecamatan Andong seluas 75 ha, rata-rata menghasilkan biji jarak 487 ton/th biji jarak pagar dan limbah sebesar 300 ton/th berupa daun, batang, kulit biji jarak. Adapun lahan pertanian 108 ha menghasilkan padi 548 ton/th, limbah sekam padi sebesar 137 ton/th, limbah jerami basah sebesar 60 ton/ha dan jerami kering 40 ton/ha. Begitu pula dengan limbah tempurung kelapa di pasar tradisional yang melimpah. Limbah tersebut hanya sebagian kecil yang dimanfaatkan, sebagian besar hanya ditumpuk dan dibuang di sungai, sekitar tempat penggilingan, di areal persawahan atau dibakar. Hal ini mengakibatkan pencemaran lingkungan. Dalam kondisi seperti ini sangat dibutuhkan teknologi pengolahan limbah tersebut menjadi briket sebagai bahan bakar alternatif yang praktis, mudah, murah dan ramah lingkungan. Selanjutnya, dengan teknologi 
pengolahan briket dari limbah biomassa ini dapat memenuhi kebutuhan bahan bakar di masyarakat dan dapat meminimasi pencemaran lingkungan.

Masalah ekonomi dan lingkungan untuk mengurangi emisi gas $\mathrm{CO}_{2}$ dari rumah kaca dan meningkatkan fleksibilitas bahan bakar telah memotivasi penggunaan bahan bakar biomassa sebagai pengganti bahan bakar fosil untuk panas dan pembangkit listrik (Jianfeng dkk., 2010). Penelitian tentang pengolahan biji jarak menghasilkan randemen kayu sebesar 30\%. Rendemen yang besar tersebut akan diperoleh 70\% limbah atau bungkil jarak pagar yang masih mengandung sisa kayu yang cukup tinggi (Budiman dkk., 2008).

Penelitian tentang briket dari biomassa sebagai bahan bakar alternatif untuk mengurangi krisis energi juga dilakukan Gomez dkk. (2014), dengan cara membangun Digital Elevation Model dari briket yang terbuat dari batang jagung dicampur serbuk kayu gergaji, sekam padi, tunas tanaman rambat, jerami. Penelitian tentang biomassa juga dilakukan oleh Longjian dkk. (2009) yang menunjukkan bahwa sumber daya limbah pertanian yang melimpah dapat digunakan sebagai bahan baku yang ekonomis dan berkelanjutan untuk pengembangan bahan bakar padat di Cina. Adapun hasil penelitian Jianfeng dkk. (2010) menunjukkan bahwa di antara berbagai teknologi konversi, pembakaran merupakan cara yang paling umum dan dikembangkan untuk mengkonversi bahan bakar biomassa menjadi energi. Korelasi baru dikembangkan untuk menghitung komposisi unsur biomassa berdasarkan analisis proksimat sederhana dalam kisaran tertentu dari FC $(9,2-32,79 \%)$, VM $(57,2-90,6 \%)$ dan ASH $(0,1-24,6 \%)$ dapat digunakan sebagai acuan.

Penelitian yang dilakukan Stolarski dkk. (2013), menunjukkan bahwa nilai kalor tertinggi telah diperoleh briket dari serbuk gergaji $(18,144$ $\left.m j \mathrm{t}^{-1}\right)$. Briket serbuk gergaji memiliki pengaruh $0,40 \%$ terhadap kandungan abu. Sementara itu, hasil penelitian Jianfeng dkk. (2012), menunjukkan bahwa ketika massa sampel sekam padi 0,6 g, ukuran tekanan oksigen adalah 3,0 $\mathrm{MPa}$, dan rasio berat sekam padi dengan asam benzoat adalah 1,2 : 1, nilai kalor sekam padi yang dihasilkan lebih tinggi mencapai nilai maksimal, yaitu $15.944 \pm 55$ $\mathrm{J} / \mathrm{g}$. Nilai kalor yang diukur dalam penelitian ini lebih tinggi dari acuan yang ditentukan masingmasing dalam standar pengujian Inggris dan Cina.

Penelitian Zhang dan Guo (2014), menunjukkan bahwa ukuran partikel merupakan faktor paling utama yang mempengaruhi sifat fisis briket, diikuti kandungan air dan suhu. Briket berkualitas adalah briket yang mempunyai ukuran partikel kecil, kandungan air rendah dan memiliki nilai kalor tinggi. Penelitian ini sejalan dengan Saptoadi (2008), tentang dimensi dan ukuran partikel pada biobriket terbaik. Hasil penelitian menunjukkan bahwa dimensi briket harus sekecil mungkin, tetapi partikel penyusun briket harus yang paling kasar.

Hasil pengujian energi alternatif biomassa yang dilakukan Simone dkk. (2014), dengan cara pendidihan air memiliki rata-rata efisiensi termal $18 \%$, selanjutnya untuk pengujian memasak membutuhkan 4,2 MJ per $\mathrm{kg}$ makanan yang dimasak. Lebih lanjut penelitian Simone dkk., (2014) tentang energi alternatif rumah tangga tersebut difokuskan untuk membantu akses energi di tingkat rumah tangga yang berpenghasilan rendah, dengan memanfaatkan limbah pertanian sebagai bahan bakar ditinjau dari aspek teknis dan ekonomi. Efisiensi yang dicapai berkisar $15-20 \%$.

Dalam penelitian pembuatan briket ini, limbah biomassa yang digunakan sebagai bahan baku khususnya sekam padi dan tempurung kelapa diakukan karbonisasi terlebih dahulu. Proses karbonisasi yang dilakukan dapat meningkatkan kandungan karbon dan nilai kalor briket. Selain itu juga dapat mengurangi emisi $\mathrm{CO}$ dan laju pembakaran. Penekanan yang tinggi selama pembriketan juga dapat mengurangi emisi $\mathrm{CO}$ dan laju pembakaran (Surono, 2010).

Penelitian tentang penggunaan metode Taguchi pada briket dari serbuk jerami telah dilakukan oleh Chau dkk. (2009). Hasil penelitian menunjukkan bahwa persentase kontribusi masingmasing faktor terkendali telah sesuai yang ditentukan. Percobaan konfirmasi dilakukan sesuai dengan kondisi optimum. Ukuran jerami padi merupakan faktor yang paling berpengaruh untuk menentukan kualitas briket dan nilainya mencapai $43 \%$. Pendekatan Taguchi pada rancangan eksperimen diharapkan mampu menghasilkan pengembangan kualitas yang kokoh (robust) terhadap faktor noise (Thomas dkk., 2011).

Meskipun penelitian mengenai nilai kalor biobriket dari limbah pertanian telah banyak dilakukan, namun penelitian mengenai nilai kalor biobriket menggunakan metode Taguchi masih jarang dilakukan, karena metode Taguchi mampu menghasilkan pengembangan kualitas yang kokoh (robust) terhadap faktor noise. Penelitian tentang metode Taguchi yang diterapkan pada kuat tekan biobriket yang dilakukan Yuwono dkk. (2010), menunjukkan bahwa kuat tekan optimal biobriket dicapai pada komposisi limbah jarak 58\%, komposisi arang sekam 35\%, komposisi larutan pati $17 \%$, tekanan pengepressan $200 \mathrm{~kg} / \mathrm{cm}^{2}$, waktu penahanan 60 menit dan waktu pengeringan 3 hari. 
Penerapan metode Taguchi yang diaplikasikan pada penelitian kadar air briket yang dilakukan Putro dkk. (2013), menunjukkan bahwa parameter terbaik yang dapat meminimalkan kadar air biobriket adalah komposisi limbah jarak pagar 60 g, komposisi arang sekam $40 \mathrm{~g}$, komposisi serbuk gergaji $40 \mathrm{~g}$, komposisi arang tempurung kelapa $20 \mathrm{~g}$, perekat tetes tebu dan suhu pengeringan 105 ${ }^{\circ} \mathrm{C}$. Pada respon kadar air biobriket, rata-rata kadar air biobriket sebesar 7,078\%. Hal ini mengkondisikan bahwa biobriket hasil penelitian mampu meminimasi kadar air sehingga dapat menaikkan nilai kalor.

Penelitian yang dilakukan Putro dkk. (2014), tentang tentang kadar air briket menunjukkan bahwa persen kontribusi yang diberikan oleh tekanan, waktu penahanan, komposisi limbah: perekat dan suhu pengeringan masing-masing sebesar 6,97; 43,19; 18,76 10,65 dan 19,37\%. Pada respon kadar air, rata-rata kadar air biobriket sebesar $7,53 \%$ artinya memenuhi standar SNI (maksimum 10\%), sehingga biobriket hasil penelitian memiliki karakteristik yang baik sebagai bahan bakar alternatif.

Penelitian tentang briket juga dilakukan oleh Saptoadi (2008). Hasil penelitian menunjukkan bahwa, porositas rendah akan menghambat pengeringan, devolatilisasi dan proses pembakaran arang karena untuk difusi massal, ruang bebas lebih sedikit. Akibatnya laju pembakarannya akan lebih rendah dan waktu pembakaran lebih lama. Rata-rata pembakaran briket dari partikel terbesar hanya membutuhkan 19,25 detik, sedangkan partikel terkecil bereaksi sampai 28 detik.

Penelitian eksperimental telah dilakukan oleh Saptoadi dkk. (2009), untuk membandingkan karakter pembakaran perilaku bahan dan pirolisis limbah organik. Pirolisis dapat meningkatkan fraksi karbon dan nilai kalor limbah. Karakteristik pembakaran yang diamati adalah pengurangan massa, laju pembakaran, temperatur gas pembakaran, dan emisi CO. Percobaan pembakaran dilakukan pada temperatur dinding tungku konstan yaitu $400{ }^{\circ} \mathrm{C}$ dan kecepatan udara konstan yaitu 0,3 $\mathrm{m} /$ detik.

Penelitian yang terkait dengan kempa panas yang dilakukan Subarmono dkk. (2011), menunjukkan bahwa sifat mekanis dari komposit ditinjau dari kekuatan tekuk dan kekerasan vickers meningkat, porositas dan tingkat keausan menurun seiring dengan peningkatan abu terbang mencapai $12,5 \%$ berat. Adapun di atas $12,5 \%$ berat abu terbang tersebut sifat mekanik komposit tampak sebaliknya. Sifat-sifat AMC/12,5\% berat, abu terbang diproduksi memakai kempa panas menunjukkan sifat terbaik pada kuat tekuk, kekerasan Vickers, porositas dan laju tahanan, masing-masing sebesar $302 \mathrm{MPa}, 79 \mathrm{VHN}, 0,73 \%$ dan $0,0095 \mathrm{mg} /(\mathrm{MPa}, \mathrm{m})$.

Penelitian terkait dengan abu terbang yang dilakukan Subarmono (2011), menunjukkan bahwa piston yang dibuat dari bahan aluminum fine powder (serbuk aluminium) dicampur serbuk tembaga dengan persen berat $1 \%$, sebagai matrix dan abu terbang lokal sebagai penguat. Hasil pengujian menunjukkan bahwa kekerasan piston 65 VHN, porositas pada kepala piston $4,3 \%$, porosistas pada bagian bawah piston $15 \%$ serta simpangan ukuran antara $0,6 \%$ dan $2 \%$.

Bertitik tolak dari permasalahan penanganan dan pengolahan biomassa menjadi briket sebagai bahan bakar alternatif, maka rumusan masalah dalam penelitian ini adalah mengoptimalkan proses pembuatan biobriket biomassa yang memiliki karakteristik terbaik dalam rangka menciptakan briket bahan bakar alternatif yang ramah lingkungan. Penelitian berfokus pada pengolahan limbah biomassa ini bertujuan untuk mengoptimalkan proses pembuatan biobriket biomassa agar memiliki karakteristik terbaik sebagai bahan bakar alternatif yang ramah lingkungan dalam mewujudkan Masyarakat Mandiri Energi.

\section{METODE PENELITIAN}

\section{Bahan dan Peralatan}

Bahan yang digunakan untuk membuat briket dalam penelitian ini adalah limbah jarak pagar (Jatropha Curcas) meliputi daun, akar, batang, dan kulit, serta arang sekam padi, arang tempurung kelapa, larutan pati dengan perbandingan 5:3:2:1 dan 5:2:3:2. Bahan limbah biomassa tersebut diperoleh dari Desa Gondangrawe, Kecamatan Andong, Kabupaten Boyolali. Adapun bahan untuk titrasi pada saat uji nilai kalor adalah menggunakan indikator metil oranye.

Peralatan yang digunakan pada proses pembriketan antara lain : mesin press biobriket, crusher, tungku elektrik, timbangan, stop watch, cangkul, bak, pengaduk, alat karbonisasi, oven. Adapun peralatan untuk pengujian nilai kalor adalah seperangkat kalorimeter bom. Beberapa peralatan tersebut ditunjukkan pada Gambar 1.

\section{Prosedur Penelitian}

Penelitian ini dilakukan dalam beberapa tahapan, yaitu pengecilan ukuran limbah jarak pagar, karbonisasi sekam padi dan tempurung kelapa, pengecilan ukuran arang sekam dan tempurung kelapa, pengayakan, pencampuran bahan dengan perekat, dan pengepresan. Selanjutnya dilakukan proses pengeringan dan pengujian nilai kalor. Prosedur pembuatan briket dilakukan dengan proses seperti uraian berikut. 

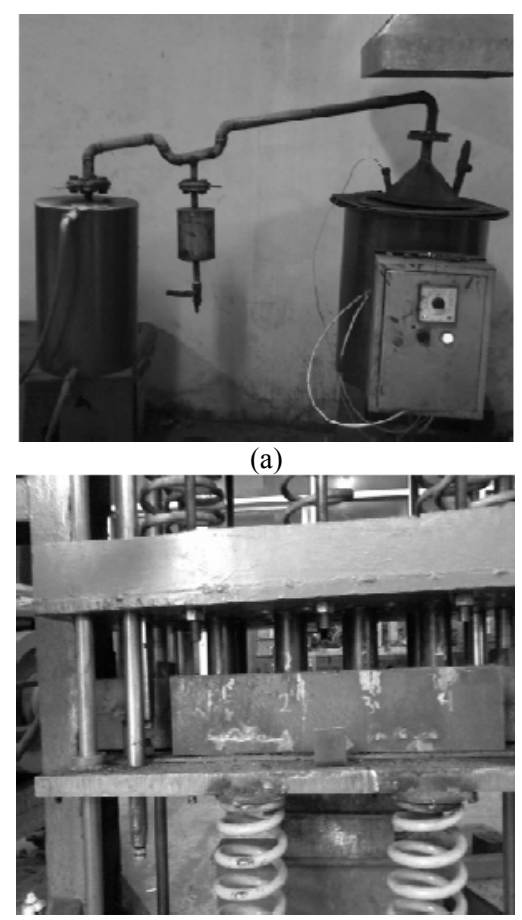

(b)

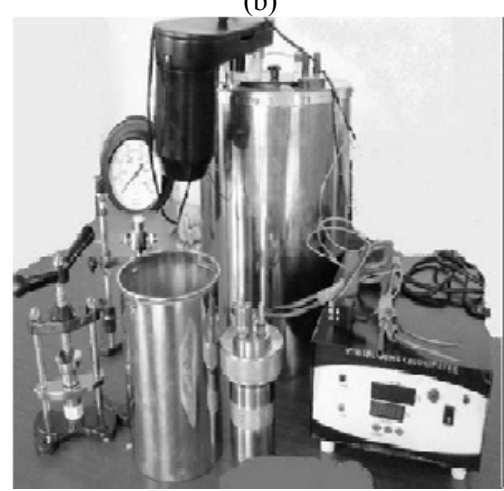

(c)

Gambar 1. Peralatan penelitian yang terdiri dari (a) alat karbonisasi, (b) mesin press, (c) kalorimeter bom.

Limbah jarak pagar, arang sekam padi, arang tempurung kelapa ditimbang dengan perbandingan 5:3:2 dan 5:2:3 dari total berat briket $(600 \mathrm{~g})$ untuk cetakan sarang tawon (kotak) dan $100 \mathrm{~g}$ untuk cetakan silindris. Selanjutnya ditambahkan dengan perekat yang telah dicampur dengan air dan dipanaskan pada tungku elektrik. Bahan tersebut dicampur hingga homogen. Campuran bahan tersebut dimasukkan dalam cetakan mesin press.

Pada saat pengepresan, tekanan diatur dan divariasikan pada $200 \mathrm{~kg} / \mathrm{cm}^{2}$ dan $225 \mathrm{~kg} / \mathrm{cm}^{2}$. Selanjutnya setelah terjadi pengepresan pada tekanan yang ditentukan, dilakukan penahanan selama waktu yang ditentukan yaitu 5 menit dan 7,5 menit agar briket menjadi lebih padat.

Setelah pencetakan selesai, briket dikeluarkan dari cetakan dan selanjutnya dilakukan pengeringan menggunakan oven pada variasi temperatur $50{ }^{\circ} \mathrm{C}$ dan $60{ }^{\circ} \mathrm{C}$. Pengeringan dilakukan sesuai variasi yang ditentukan yaitu 2 hari dan 3 hari.

Selanjutnya, briket dikeluarkan dari oven dan dilakukan pengujian nilai kalor. Dalam pengujian nilai kalor ini terdiri dari 3 tahap yaitu persiapan alat, pengukuran dan pembongkaran. Setelah dilakukan pengujian nilai kalor, kemudian dibuat perhitungan nilai kalor yang menggunakan ASTM D-2015. Hasil nilai kalor yang diperoleh selanjutnya diolah menggunakan persamaan pada metode Taguchi dengan karakteristik kualitas lebih tinggi lebih baik artinya semakin tinggi nilai kalor briket, kualitas briket semakin baik dan semakin disukai.

\section{Desain Penelitian}

Model yang digunakan untuk mengetahui kualitas biobriket ditinjau dari nilai kalor $(\hat{\mathrm{Y}})$ menggunakan enam variabel bebas ( tekanan pengepresan, waktu penahanan, model mould, suhu pengeringan, lama pengeringan dan komposisi limbah ) adalah sebagai berikut :

$\hat{\mathrm{Y}}_{\mathrm{ijklmn}}=\mu+\overline{\mathrm{A}}_{\mathrm{i}}+\overline{\mathrm{B}}_{\mathrm{j}}+\overline{\mathrm{C}}_{\mathrm{k}}+\overline{\mathrm{D}}_{1}+\overline{\mathrm{E}}_{\mathrm{m}}+\overline{\mathrm{F}}_{\mathrm{n}}+\varepsilon_{\mathrm{o}(\mathrm{j} \mathrm{jklmn})}$

Berdasarkan ANOVA untuk menentukan setting parameter yang tepat agar dihasilkan nilai kalor biobriket yang tinggi dapat diterapkan metode Taguchi.

\section{Metode Taguchi}

Metode taguchi berkembang berdasarkan pendekatan yang secara keseluruhan berbeda dengan metode konvensional dalam rekayasa kualitas. Dalam pengendalian kualitas Taguchi telah menggabungkan falsafah-falsafah besar pada industri manufaktur (Nicolo, 1995). Pendekatan Taguchi pada rancangan eksperimen diharapkan mampu menghasilkan pengembangan kualitas yang kokoh (robust) terhadap faktor noise (Thomas dkk., 2011). Hasil eksperimen konfirmasi akan menentukan apakah level faktor optimal yang diperoleh bisa diperluas ke skala industri. Menurut Pal dan Gauri (2010), dalam Ross (1998), fungsi kerugian dibedakan menjadi tiga jenis yaitu :

1. Smaller the better $: \mathrm{L}(\mathrm{y})=\mathrm{k}(\mathrm{y}-\mathrm{m})^{2}$

2. Nominal the better : $\mathrm{L}(\mathrm{y})=\mathrm{k}(\mathrm{y})^{2}$

3. Larger the better: $\mathrm{L}(\mathrm{y})=\mathrm{k}(1 / \mathrm{y})^{2}$

\section{HASIL DAN PEMBAHASAN}

Dalam eksperimen ini, dilakukan kombinasi dari pembentuk biobriket yaitu tekanan pengepressan, waktu penahanan, model mould, suhu pengeringan, lama pengeringan, perbandingan limbah jarak pagar : arang sekam : arang tempurung kelapa : perekat. Dalam percobaan ini, masing-masing 4 (empat) kali 
replikasi, selanjutnya dilakukan uji nilai kalor. Hasil pengujian nilai kalor yang ditransformsi dalam Ratio SN disajikan pada Tabel 1.

Ratio S/N merupakan logaritma dari rata-rata kuadrat simpangan dari nilai target atau hasil transformasi dari beberapa replikasi data sehingga nilainya mewakili kualitas penyajian variasi. Nilai Rasio S/N tertinggi dicapai pada nilai 14, 389 yaitu pada eksperimen ke 6 . Hal ini sesuai dengan hasil penelitian Chau dkk. (2009) tentang penentuan Rasio S/N pada densitas briket padat dari jerami padi yang memiliki nilai densitas terbesar adalah 60,09 pada percobaan ke -9 .

\section{Analisis Variansi Respon Nilai Kalor Biobriket}

Dalam mengoptimalkan proses pembuatan biobriket, agar dihasilkan nilai kalor yang tinggi sesuai yang dibutuhkan masyarakat dalam mewujudkan Masyarakat Mandiri Energi menggunakan karakteristik kualitas lebih tinggi nilai kalor briket lebih baik. Faktor-faktor yang berpengaruh signifikan pada respon nilai kalor biobriket ditunjukkan Tabel 2.

Variabel respon dalam penelitian ini adalah nilai kalor biobriket yang mempunyai karakteristik kualitas lebih besar lebih baik, artinya semakin tinggi nilai kalor biobriket, semakin disukai karena biobriket kandungan unsur $\mathrm{C}$ semakin besar dan kadar air semakin kecil, sehingga laju penyalaan semakin tinggi. Dalam upaya mengetahui faktor utama yang berpengaruh signifikan terhadap variabel respon nilai kalor biobriket, maka digunakan analisis varians (ANOVA). Data yang digunakan dalam ANOVA telah ditransformasi ke dalam ratio $\mathrm{S} / \mathrm{N}$ (signal to noise).

Tabel 1. Ratio $\mathrm{S} / \mathrm{N}$ nilai kalor biobriket.

\begin{tabular}{cc}
\hline Kondisi & Ratio S/N \\
\hline Percobaan \# 1 & 14,005 \\
Percobaan \# 2 & 14,279 \\
Percobaan \# 3 & 14,067 \\
Percobaan \# 4 & 14,195 \\
Percobaan \# 5 & 14,230 \\
Percobaan \# 6 & 14,389 \\
Percobaan \# 7 & 14,315 \\
Percobaan \# 8 & 14,013 \\
Rerata performansi & 14,187 \\
\hline
\end{tabular}

Faktor-faktor yang diuji pengaruhnya pada nilai kalor biobriket menggunakan ANOVA adalah tekanan pengepresan (A), waktu penahanan (B), model mould (C), suhu pengeringan (D), lama pengeringan (E), perbandingan limbah jarak pagar : arang sekam: arang tempurung kelapa: perekat (F). Hasil penelitian terkait dengan komposisi limbah biomassa ini sesuai dengan Budiman, dkk., (2008) yang menyatakan bahwa perbandingan biobriket tersebut yang telah memenuhi standar spesifikasi briket batubara tanpa karbonisasi yaitu perbandingan campuran $(80: 20)$ dan $(90: 10)$.

Hasil pengujian hipotesis berdasarkan Tabel 2 ANOVA menunjukkan bahwa PValue_A = $13,715 \%>5 \%$, maka menolak Ho, yaitu ada pengaruh perbedaan level dari tekanan pengepressan terhadap nilai kalor biobriket. Selanjutnya, pengaruh perbedaan level pada faktor B, C, D, E, F pada nilai kalor biobriket masingmasing sebesar $8,451 \%, 6,194 \%, 5,675 \%, 25,462 \%$ dan $31,651 \%$. Hasil penelitian yang terkait dengan variabel penelitian tekanan ini sesuai dengan hasil penelitian Jianfeng dkk. (2012), dimana pada massa sampel sekam padi 0,6 g, sekam padi : asam benzoat adalah 1,2:1 dibutuhkan tekanan oksigen 3 $\mathrm{MPa}$, untuk, menghasilkan nilai kalor sekam padi $15.944 \pm 55 \mathrm{~J} / \mathrm{g}$.

Adapun hasil penelitian yang terkait dengan ANOVA ini sesuai dengan hasil penelitian Chau dkk. (2009) yang menunjukkan bahwa faktor yang berpengaruh signifikan memiliki persen kontribusi $43 \%$. Hasil ANOVA khususnya pada parameter waktu pengeringan pada briket ini juga sesuai dengan penelitian Yuwono dkk. (2010) yang membutuhkan waktu 3 hari.

\section{Efek Utama}

Rata-rata efek faktor merupakan selisih nilai kalor tiap level pada setiap faktor utama yang mempengaruhi nilai kalor biobriket dengan karakteristik kualitas lebih tinggi lebih baik seperti ditunjukkan pada Tabel 3. Hubungan nilai kalor, rerata nilai kalor dan nilai efek setiap faktor pada tiap level untuk setting parameter optimal pembentuk biobriket ditunjukkan dalam Gambar 2.

\begin{tabular}{lccccc}
\hline \multicolumn{1}{c}{ Kolom \#/ Faktor } & $\begin{array}{c}\text { Derajat } \\
\text { bebas (f) }\end{array}$ & $\begin{array}{c}\text { Jumlah } \\
\text { kuadrat (S) }\end{array}$ & $\begin{array}{c}\text { Variansi } \\
(\mathrm{V})\end{array}$ & $\mathrm{S}^{\prime}$ & $\begin{array}{c}\text { Persentase } \\
\text { kontribusi (P) (\%) }\end{array}$ \\
\hline A: Tekanan pengepresan & 1 & 0,019 & 0,019 & 0,019 & 13,715 \\
B: Waktu penahanan & 1 & 0,012 & 0,012 & 0,012 & 8,451 \\
C: Model mould & 1 & 0,008 & 0,008 & 0,008 & 6,194 \\
D: Suhu pengeringan & 1 & 0,008 & 0,008 & 0,008 & 5,675 \\
E: Lama pengeringan & 1 & 0,036 & 0,036 & 0,036 & 25,462 \\
F: Limbah jarak pagar : arang & 1 & 0,045 & 0,045 & 0,045 & 31,651 \\
$\quad$ sekam : arang tempurung & & & & & \\
$\quad$ kelapa:perekat & 1 & 0,012 & 0,012 & 0,012 & 8,496 \\
Error & 7 & 0,145 & & & $100,00 \%$ \\
Total & & & & & \\
\hline
\end{tabular}


Tabel 3. Main effect nilai kalor biobriket.

\begin{tabular}{|c|c|c|c|}
\hline Kolom \#/Faktor & Taraf 1(L1) & Taraf 2 (L2) & L2 - L1 \\
\hline A: Tekanan pengepresan & 14,137 & 14,237 & 0,009 \\
\hline B: Waktu penahanan & 14,226 & 14,147 & $-0,08$ \\
\hline C: Model mould & 14,154 & 14,219 & 0,064 \\
\hline D: Suhu pengeringan & 14,119 & 14,225 & 0,136 \\
\hline E: Lama pengeringan & 14,111 & 14,263 & 0,151 \\
\hline F: Limbah jarak pagar : arang sekam : arang tempurung kelapa : perekat & 14,226 & 14,147 & $-0,08$ \\
\hline
\end{tabular}

Tabel 4. Kondisi optimum nilai kalor biobriket.

\begin{tabular}{lccc}
\hline Kolom \#/Faktor & Keterangan taraf & Taraf & Kontribusi \\
\hline A: Tekanan pengepresan & $225 \mathrm{~kg} / \mathrm{cm}^{2}$ & 2 & 0,285 \\
B: Waktu penahanan & 5 menit & 1 & 0,167 \\
C: Model mould & Sarang tawon (box) & 2 & 0,150 \\
D: Suhu pengeringan & $60^{\circ} \mathrm{C}$ & 2 & 0,339 \\
E: Lama pengeringan & 3 hari & 2 & 0,316 \\
F: Limbah jarak pagar : arang sekam : & $5: 3: 2: 1$ & 1 & 0,039 \\
$\quad$ arang tempurung kelapa : perekat & & & 0,338 \\
Total Kontribusi dari seluruh faktor & & & 14,187 \\
Rata-rata performansi & & & 14,525 \\
Hasil optimum yang diharapkan & & & \\
\hline
\end{tabular}

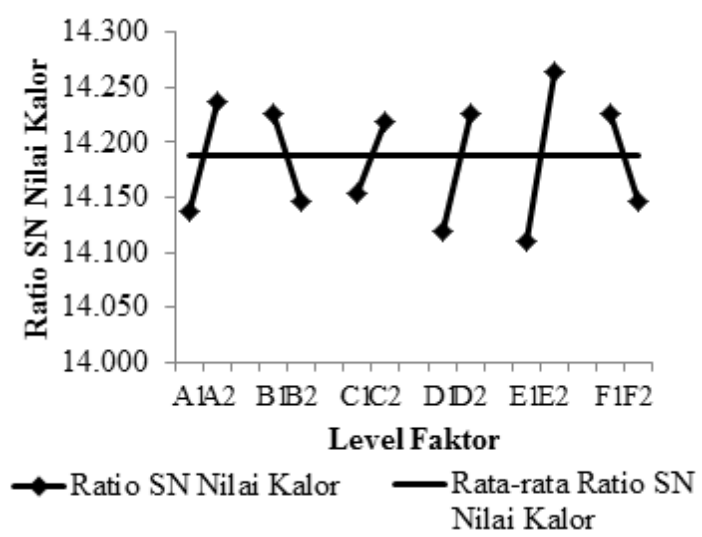

Gambar 2. Efek faktor utama ratio SN Nilai kalor.

\section{Kondisi Optimum Pembuatan Biobriket pada Nilai Kalor tertinggi}

Kondisi optimum pembentuk biobriket yang menghasilkan nilai kalor tinggi pada biobriket dengan memvariasikan 6 (enam) faktor utama diperoleh pada kondisi A2B1C2D2E2F1 seperti ditunjukkan pada Tabel 4.

Kondisi optimum berguna untuk mengetahui level dari setiap faktor sehingga respon nilai kalor biobriket dapat dimaksimalkan. Faktor-faktor yang berpengaruh positif terhadap respon nilai kalor biobriket pada percobaan utama adalah tekanan pengepressan (A), waktu penahanan (B), model mould (C), suhu pengeringan (D), lama pengeringan (E), perbandingan limbah jarak pagar: arang sekam: arang tempurung kelapa: perekat (F). Kondisi optimum dipilih untuk setiap level yang memberikan nilai rata-rata rasio $\mathrm{S} / \mathrm{N}$ yang tertinggi. Hasil penelitian ini sesuai dengan penelitian Yuwono dkk. (2011) dan Thomas dkk. (2011), bahwa produk harus robust terhadap faktor noise.
Berdasarkan Tabel 4, kondisi optimum proses pembuatan biobriket untuk meningkatkan nilai kalor biobriket sebagai bahan bakar alternatif adalah A2B1C2D2E2F1. Parameter tersebut adalah tekanan pengepressan $225 \mathrm{~kg} / \mathrm{cm}^{2}$, waktu penahanan 5 menit, model mould sarang tawon (box), suhu pengeringan $60^{\circ} \mathrm{C}$, lama pengeringan 3 hari, perbandingan limbah jarak pagar : arang sekam : arang tempurung kelapa : perekat adalah 5:3:2:1. Hasil penelitian ini sesuai penelitian Putro dkk. (2013); Putro dkk. (2014), tentang meminimasi kadar air briket dibutuhkan setting parameter yang tepat.

Transformasi kondisi optimum pembuatan biobriket pada nilai kalor tertinggi disajikan dari perhitungan berikut. Estimasi hasil yang diharapkan dari ratio $\mathrm{S} / \mathrm{N}$ dengan target value :

$\mathrm{Yo}=14,187$

$\mathrm{S} / \mathrm{N}=-10 \log (\mathrm{MSD})=14,523$

$\mathrm{MSD}=10^{\wedge}[-(\mathrm{S} / \mathrm{N}) / 10=0,035294$

$\mathrm{Y}$ ekp $=5,323 \mathrm{QC}$ Unit

(Berdasarkan pada kondisi optimum pada rasio $\mathrm{S} / \mathrm{N}=14,523)$.

\section{Distribusi pada Nilai Kalor Biobriket}

Grafik pengurangan variasi nilai kalor biobriket merupakan perbandingan kondisi awal sebelum dilakukan setting parameter dengan kondisi perbaikan disajikan dalam Gambar 3. Ratarata nilai kalor biobriket yang dihasilkan sebesar $5,323 \mathrm{kal} / \mathrm{g}$ (x1.000). Penelitian nilai kalor ini sesuai dengan hasil penelitian Changdong dan Azevedo (2005), yang menyatakan bahwa, nilai kalor merupakan salah satu sifat paling penting dalam bahan bakar yang berasal dari biomassa di dalam perhitungan maupun simulasi numerik pada 


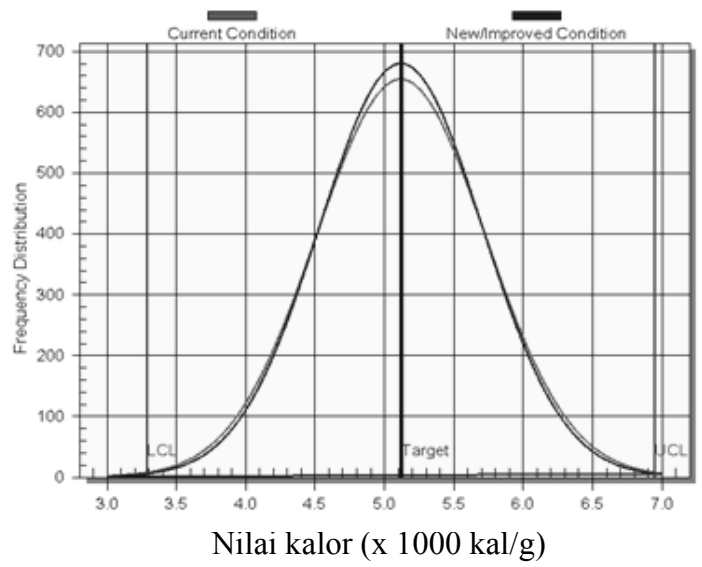

Gambar 3. Grafik pengurangan variasi nilai kalor.

sistem konversi thermal. Penelitian ini juga sesuai dengan Stolarski dkk. (2013), bahwa nilai kalor tertinggi telah diperoleh pada briket dari serbuk gergaji.

Pada kondisi awal nilai rasio $\mathrm{S} / \mathrm{N}$ sebesar 14,187. Setelah dilakukan optimasi, nilai Ratio S/N naik menjadi 14,525, sedangkan nilai $\mathrm{Cp}$ dan $\mathrm{Cpk}$ mengalami peningkatan signifikan menjadi 1,039 . Biobriket hasil penelitian memiliki nilai kalor tinggi dan memenuhi SNI yang ditetapkan. Hasil penelitian ini sesuai penelitian Zhang dan Guo (2014), yaitu briket berkualitas baik dapat dibuat dengan ukuran partikel yang kecil, kandungan air rendah dan kondisi temperatur tinggi.

\section{KESIMPULAN}

Hasil penelitian menunjukkan bahwa rata-rata nilai kalor briket telah memenuhi SNI. Dengan demikian, briket yang dihasilkan layak digunakan untuk memenuhi kebutuhan bahan bakar alternatif yang memiliki nilai kalor tinggi dan ramah lingkungan. Proses pembuatan briket tergolong dalam kategori capable, hal ini ditunjukkan pada nilai $\mathrm{Cp}$ dan Cpk yang meningkat dari kondisi awal. Metode Taguchi yang digunakan untuk menentukan setting parameter yang tepat pada proses pembuatan briket, mampu menghasilkan kombinasi parameter terbaik sebagai model dan acuan dalam pembriketan skala yang lebih besar. Dengan demikian permasalahan pencemaran lingkungan yang disebabkan oleh limbah biomassa dapat diminimalisir dengan cara pengolahan limbah biomassa menjadi briket yang ekonomis dan ramah lingkungan.

\section{UCAPAN TERIMAKASIH}

Dalam kesempatan ini, tim peneliti ingin mengucapkan terima kasih kepada DP2M Dirjen
Dikti Kementerian Pendidikan Nasional Republik Indonesia, atas dukungan dana penelitian ini melalui skema penelitian Hibah Bersaing Tahun Anggaran 2013-2014 dengan no kontrak : 053/K6/ SP/PENELITIAN/2014.

\section{DAFTAR PUSTAKA}

Anonim, 2007. BPS Kabupaten Boyolali. Boyolali. Budiman, S., Sukrido, dan Harliana, A., 2008. Pembuatan Biobriket dari Campuran Bungkil Jarak Pagar (Jatropha Curcas.L) dengan Sekam sebagai Bahan Bakar Alternatif. Prosiding Seminar Rekayasa Kimia dan Proses, Teknik Kimia, Universitas Diponegoro, Semarang.

Changdong, S., dan Azevedo, J.L.T., 2005. Estimating the Higher Heating Value of Biomass Fuels from Basic Analysis Data. Biomass and Bioenergy, 28:499-507.

Chou, S.C., Lin, H.S., Peng, C.C., dan Lu, C.W., 2009. The Optimum Conditions for Preparing Solid Fuel Briquette of Rice Straw by a Piston-Mold Process using the Taguchi Method. Fuel Processing Technology, 90:1041-1046.

Gómez, R., Gallego, E., Fuentesa, J.M., Montellano, G.C., dan Ayuga, F., 2014. Values for Particle-Scale Properties of Biomass Briquettes Made from Agroforestry Residues. Particuology, 12:100-106.

Jianfeng, S., Shuguang, Z., Xinzhi, L., Houlei, Z., dan Junjie, T., 2010. The Prediction of Elemental Composition of Biomass Based on Proximate Analysis. Energy Conversion and Management, 51:983-987.

Jianfeng, S., Shuguang, Z., Xinzhi, L., Houlei, Z., dan Junjie, T., 2012. Measurement of Heating Value of Rice Husk by Using Oxygen Bomb Calorimeter with Benzoic Acid as Combustion Adjuvant. Energy Procedia, 17:208-213.

Longjian, C., Xing, L., dan Lujia, H., 2009. Renewable Energy from Agro-Residues in China: Solid Biofuels and Biomass Briquetting Technology Renewable and Sustainable Energy Reviews. Renewable and Sustainable Energy, 13:2689-2695.

Nicolo, B., 1995. Quality by Design Taguchi Techniques for Industrial Experimentation. Prentice Hall International, London.

Pal, S., dan Gauri, S.K., 2010. Assessing Effectiveness of the Various Performance Metrics for Multi-Response Optimization using Multiple Regression. Journal of Computers \& Industrial Engineering, 59:976985. 
Putro, S., Musabbikhah, dan Hartati, S., 2013. Variasi Parameter Biomassa untuk Meminimasi Kadar Air Biobriket Guna Menciptakan Energi Alternatif yang Murah dan Ramah Lingkungan. Prosiding Simposium Nasional RAPI ke XII, 5 Desember 2013, Universitas Muhammadiyah Surakarta, Surakarta, hal 79-86.

Putro, S., Musabbikhah, dan Hartati, S., 2014. Setting Parameter yang Optimal pada Proses Pembriketan Limbah Biomassa Guna Mendapatkan Kadar Air Briket Minimal dalam Menciptakan Enegri Altrenatif yang Ekonomis. Prosiding Simposium Nasional RAPI ke XIII, 4 Desember 2014, Universitas Muhammadiyah Surakarta, Surakarta, hal 7076.

Ross, P.J., 1998. Taguchi Techniques for Quality Engineering. Second Edition, MC Graw Hill Book Company, New York.

Saptoadi, H., 2008. The Best Biobriquette Dimension and its Particle Size. Asian J. Energy Environ. 9:161-175.

Saptoadi, Untoro, B., Surono, Nugroho, A., Pambudi, dan Sudarwanto, 2009. Utilization of Indigenous Biomass Wastes as Low Cost Alternative Fuels. International Conference on Alternative Energy Applications, Nopember 25, Kuwait.

Simone, P.P., Francesco, V., Adriano, M.L., dan Mentore, V., 2014. Design and Performance Assessment of a Rice Husk Fueled Stove for Household Cooking in A Typical Sub-Saharan Setting. Energy for Sustainable Development, 23:15-24.

Stolarski, M.J., Szczukowski, S., Tworkowski, J., Krzyzaniak, M., Gulczynski, P., dan Mleczek, M., 2013. Comparison of Quality and production Cost of Briquettes Made from
Agricultural and Forest Origin Biomass. Renewable Energy, 57:20-26.

Surono, U.B., 2010. Peningkatan Kualitas Pembakaran Biomassa Limbah Tongkol Jagung sebagai Bahan Bakar Alternatif dengan Proses Karbonisasi dan Pembriketan, Jurnal Rekayasa Proses, 4(1):13-18.

Subarmono, Jamasri, Wildan, M.W., dan Kusnanto., 2010. Mechanical Properties of Alumunium Fly Ash Composites Produced by Hot Extrusion. J. Mater. Sci. Res, 7(1):95-100

Subarmono., Jamasri., Wildan, M.W., dan Kusnanto, 2011. Utilization of Fly Ash Waste as Reinforcement of Aluminium Matrix Composite Produced Using Powder Metallurgy. J. Manusia dan Lingkungan, 18(2):98-104.

Thomas, Q., Patrick, S., dan Yann, L., 2011. Development of a Trade-off Function for Robust Optimization Problems in Design Engineering. Proceedings of the IMProVe, International Conference on Innovative Methods in Product Design, 15-17 Juni, Venice, 603-611.

Wardono, 2010. Budi Daya Jarak Pagar oleh Kelompok Tani Ternak Sumber Rejeki di Boyolali, Diklat Pelatihan Usaha Tani. Boyolali.

Yuwono, T., Musabbikhah, dan Suhartoyo., 2011. Variasi Komposisi Limbah Jarak Pagar, Limbah Pertanian, Tekanan Pengepresan dan Waktu Pengeringan untuk Mengoptimalkan Kuat Tekan Biobriket dalam Rangka Mewujudkan Masyarakat Mandiri Energi. Jurnal Eksplorasi, 23(1):84-93.

Zhang, J., dan Guo, Y., 2014. Physical Properties of Solid Fuel Briquettes Made from Caragana korshinskii Kom. Powder Technology, 256:293-299. 